\title{
Ginsenoside Rg5 induces apoptosis in human esophageal cancer cells through the phosphoinositide-3 kinase/protein kinase B signaling pathway
}

\author{
DAOMING ZHANG ${ }^{1,2}$, AIFU WANG ${ }^{1}$, JUEPING FENG ${ }^{2}$, QI ZHANG ${ }^{1}$, LINLIN LIU $^{1}$ and HUI REN ${ }^{3,4}$ \\ ${ }^{1}$ Department of Radiotherapy, The Second Hospital of Jilin University, Changchun, Jilin 130041; \\ ${ }^{2}$ Department of Oncology, Wuhan Puai Hospital of Tongji Medical College, Huazhong University of Science and Technology, \\ Wuhan, Hubei 430035; ${ }^{3}$ Department of General Surgery, The China-Japan Union Hospital of Jilin University, Changchun, \\ Jilin 130000; ${ }^{4}$ Department of General Surgery, The Second Hospital of Jilin University, Changchun, Jilin 130041, P.R. China
}

Received March 21, 2018; Accepted September 28, 2018

DOI: $10.3892 / \mathrm{mmr} .2019 .10093$

\begin{abstract}
The role of ginsenoside in the prevention of cancer has been well established. Ginsenoside Rg5 is one of the main components isolated from red ginseng, which has been demonstrated to have anti-tumor effects by inhibiting cell proliferation and causing DNA damage. However, the role of ginsenoside $\operatorname{Rg} 5$ and its molecular mechanisms remain unclear in human esophageal cancer. In the present study, Rg5 was investigated as a novel drug for the chemotherapy of esophageal cancer in in vitro experiments. Esophageal cancer Eca109 cells were exposed to various concentrations of ginsenoside $\operatorname{Rg} 5$ (0-32 $\mu \mathrm{M})$ for $24 \mathrm{~h}$. Subsequent cell proliferation assays demonstrated that treatment with ginsenoside Rg5 resulted in the dose-dependent inhibition of proliferation, while a significant increase in apoptotic rate and increased activities of caspase- $3,-8$ and -9 were observed. In addition, the mitochondrial membrane potential was decreased and the cytoplasmic free calcium level increased following treatment with ginsenoside Rg5. Furthermore, the expression of B-cell lymphoma 2 and phosphorylated-protein kinase B (p-Akt) decreased. The specific phosphoinositide-3 kinase (PI3K) inhibitor LY294002 promoted this effect, while insulin-like growth factor-1, a specific PI3K activator, inhibited this action. Taken together, the results suggested that ginsenoside Rg5 may have a tumor-suppressive effect on esophageal cancer by
\end{abstract}

Correspondence to: Professor Linlin Liu, Department of Radiotherapy, The Second Hospital of Jilin University, 218 Ziqiang Street, Changchun, Jilin 130041, P.R. China

E-mail: 2660424632@qq.com

Professor Hui Ren, Department of General Surgery, The China-Japan Union Hospital of Jilin University, 2 Xiantai Street, Changchun, Jilin 130000, P.R. China

E-mail: hren@jlu.edu.cn

Key words: ginsenoside Rg5, esophageal cancer cells, apoptosis promoting apoptosis and may be associated with the downregulation of the PI3K/Akt signaling pathway.

\section{Introduction}

Ginseng, the root of Araliaceae plants, is a Chinese herbal medicine that can be divided into different categories, including wild ginseng, red ginseng and Korean ginseng among others. Panax ginseng C.A. Meyer, a native herbal remedy commonly used in China and Korea $(1,2)$, has been recognized as a life prolonging herb in Asia for thousands of years (3-5). Ginsenoside Rg5 (Fig. 1) belongs to a family of protopanaxadiol ginsenosides $(1,6)$ and has been demonstrated to exhibit marked anticancer activity $(7,8)$, antidermatitic activity (9), neuroprotective effects (10) and microglial activation (11).

Esophageal cancer is one of the most common malignancies worldwide, with a high mortality rate of $>400,000$ cases per year (12). At present, the main treatments include surgery, radiotherapy, chemotherapy and targeted therapy. Squamous cell carcinoma accounts for $>90 \%$ of the esophageal pathological classifications worldwide, closely followed by adenocarcinoma. Surgical resection remains the primary treatment; however, the 5-year overall survival rate is only $\sim 30 \%$, and the squamous cell carcinoma survival rate is $20-50 \%$. Surgical treatment is mainly limited by local recurrence and metastasis, as well as the reduction of the patients' immune function postoperatively (13). The majority of patients are diagnosed at a relatively late stage due to the lack of evident clinical symptoms during the early stages. It has been reported that $40-60 \%$ of patients are unable to undergo surgery as a result of suffering from late stage disease or due to the high risks associated with surgery (14). Local radiotherapy is one of the best treatment options for patients with local advancement. Since the development of RTOG85-01, radiotherapy combined with chemotherapy has been accepted as the optimal treatment option for non-surgical esophageal cancer patients (15). However, the search for novel drugs for the treatment of esophageal cancer remains of great significance. 
Apoptosis, also known as programmed cell death, is important for controlling cell numbers and proliferation, and is essential for the elimination of cancer cells. Apoptotic cells usually avoid chromatin condensation, forming apoptotic bodies (16). There are two major apoptotic pathways, including extrinsic or death receptor pathways, and intrinsic or mitochondrial pathways (17). These two pathways are associated with the activation of caspases, which are responsible for inducing apoptosis through nuclear DNA cleavage and regulatory cell proteins. The mitochondrial pathway is mainly regulated by members of the B-cell lymphoma 2 (Bcl-2) family, which includes proapoptotic proteins, such as Bcl-2-associated $\mathrm{X}$ protein (Bax), and antiapoptotic proteins, such as Bcl-2 and Bcl-extra large protein (18). The phosphoinositide-3 kinase $(\mathrm{PI} 3 \mathrm{~K}) /$ protein kinase B (Akt) signaling pathway has a positive role in regulating cell growth, proliferation, differentiation and cell cycle progression, and in reversing drug resistance. Activated Akt in turn activates downstream signaling pathways via phosphorylation in order to participate in the regulation of cellular physiological and biochemical changes that protect the surviving cells from undergoing apoptosis. In addition, the inactivation of Akt may contribute to the apoptosis of esophageal cancer cells.

The application of ginsenoside Rg5 in the treatment of esophageal cancer is considered to have potentially promising anti-tumor effects. Therefore, the aim of the present study was to investigate the anti-tumor effect of ginsenoside $\operatorname{Rg} 5$ on esophageal cancer cells and examine the possible molecular mechanisms in order to provide an objective basis for its function.

\section{Materials and methods}

Chemicals and reagents. Ginsenoside $\mathrm{Rg} 5$ (purity, >99\%), dissolved in $75 \%$ ethanol at a density of $10 \mathrm{mM}$ and stored at $-20^{\circ} \mathrm{C}$, was obtained from Professor Yinghua Jin (College of Life Science, Jilin University, Changchun, China). The Cell Counting Kit-8 (CCK-8) assay kit and Fluo-3/acetoxymethyl (AM) were purchased from Dojindo Molecular Technologies, Inc. (Kumamoto, Japan). The Annexin V-fluorescein isothiocyanate (FITC)/propidium iodide (PI) apoptosis assay kit and bicinchoninic acid (BCA) protein assay kit were obtained from GenStar Biosolutions Co., Ltd. (Beijing, China). Rhodamine 123 and LY294002 were purchased from Sigma-Aldrich (Merck KGaA, Darmstadt, Germany). Insulin-like growth factor (IGF)-1 was obtained from R\&D Systems Europe, Ltd. (Abingdon, UK). Rabbit polyclonal antibodies specific for cleaved caspase-3 (9661T; 1:800), Bax (5023T; 1:1,000), Bcl-2 (2872S; 1:1,000), Akt (4691S; 1:1,000), phosphorylated (p)-Akt (9611S; 1:1,000), cleaved poly(adenosine diphosphate-ribose) polymerase (PARP) (5625S; 1:1,000) were obtained from Cell Signaling Technology, Inc. (Danvers, MA, USA). Rabbit polyclonal antibodies specific for cleaved caspase-8 (YT5688; 1:1,000) and caspase-9 (YC0013; 1:1,000) were obtained from ImmunoWay Biotechnology Company (Plano, TX, USA). Antibodies specific for $\beta$-actin (E-AB-20058; 1:1,000) and horseradish peroxidase-conjugated goat anti-rabbit secondary antibodies (E-AB-1003; 1:5,000) were purchased from Elabscience Biotechnology Co., Ltd. (Wuhan, China).
Cell lines and cell culture. The human esophageal cancer cell line Eca-109 was provided by Dr Xingyi Zhang (Second Hospital of Jilin University, Changchun, China). Cells were incubated in RPMI-1640 medium with $10 \%$ fetal bovine serum, $100 \mathrm{U} / \mathrm{ml}$ penicillin and $100 \mu \mathrm{g} / \mathrm{ml}$ streptomycin under $5 \% \mathrm{CO}_{2}$ in humidified air at $37^{\circ} \mathrm{C}$.

Cell viability assay. The effect of ginsenoside $\mathrm{Rg} 5$ on the viability of cells was measured using the CCK-8 assay. Briefly, Eca-109 cells were plated at a density of 2,000 cells/well with $200 \mu \mathrm{l}$ complete culture medium in 96-well plates, and treated with $2,4,8,16$ and $32 \mu \mathrm{M}$ of ginsenoside Rg5 for $24 \mathrm{~h}$. A total of $10 \mu \mathrm{l}$ CCK-8 solution was then added to the aforementioned cell cultures according to the manufacturer's protocol. Subsequently, the plates were incubated for $2 \mathrm{~h}$ at $37^{\circ} \mathrm{C}$, and the optical density was read at a wavelength of $450 \mathrm{~nm}$ on a microplate reader (Thermo Fisher Scientific, Inc., Waltham, MA, USA). The half maximal inhibitory concentration $\left(\mathrm{IC}_{50}\right)$ value was calculated using a fitted function according to the concentration of each group and the corresponding inhibition rate. This calculation was conducted automatically using IBM SPSS software (version 22.0; IBM Corp., Armonk, NY, USA).

Analysis of apoptosis using flow cytometry. Cell apoptosis was measured with a flow cytometer using the Annexin V-FITC/PI apoptosis assay kits following the manufacturer's protocol. Following exposure to the determined concentrations of ginsenoside $\operatorname{Rg} 5$ for $24 \mathrm{~h}$, cells were collected, washed with cold PBS, and resuspended with binding buffer containing $10 \mathrm{mM}$ HEPES, $2.5 \mathrm{mM} \mathrm{CaCl}_{2}$ and $140 \mathrm{mM} \mathrm{NaCl}$. Next, cells were incubated with Annexin $\mathrm{V}$ in the dark at room temperature for $10 \mathrm{~min}$ and then resuspended in binding buffer. PI was added to the samples at $37^{\circ} \mathrm{C}$ immediately prior to analysis with a FACScan flow cytometer (Beckman Coulter, Inc., Brea, CA, USA).

Detection of mitochondrial membrane potential. Mitochondrial membrane potential was detected using rhodamine 123. Initially, Eca-109 cells were briefly treated with $\operatorname{Rg} 5$ at a concentration of 5, 10 and $20 \mu \mathrm{M}$ for $24 \mathrm{~h}$. Next, the cell suspension was routinely prepared, rinsed twice with PBS buffer, cultured with rhodamine $123(5 \mu \mathrm{g} / \mathrm{ml})$ at $37^{\circ} \mathrm{C}$ for $30 \mathrm{~min}$ and washed with PBS. The cells were collected again by centrifugation $(800 \mathrm{x} \mathrm{g}$ at $37^{\circ} \mathrm{C}$ for $5 \mathrm{~min}$ ) and resuspended with $300 \mu \mathrm{l} \mathrm{PBS}$. The fluorescence intensity of cells incubated with rhodamine 123 was finally determined by flow cytometric analysis.

Analysis of calcium levels. Calcium levels were measured using the calcium indicator Fluo-3/AM and laser scanning confocal microscopic imaging. Briefly, treated Eca-109 cells were incubated with Fluo-3/AM for $\sim 30 \mathrm{~min}$ in the dark at $37^{\circ} \mathrm{C}$, and then washed with D-Hanks medium. The fluorescence intensity was detected by confocal microscopy at $488 \mathrm{~nm}$, measuring the intensity of $\sim 5-10$ cells in each microscopic field separately. Finally, the fluorescence intensity was digitized, and all data were analyzed using the affiliated software of the confocal microscope system.

Western blot analysis. Treated cells were washed with cold PBS and extracted with lysis buffer, containing $50 \mathrm{mmol} / \mathrm{l}$ 


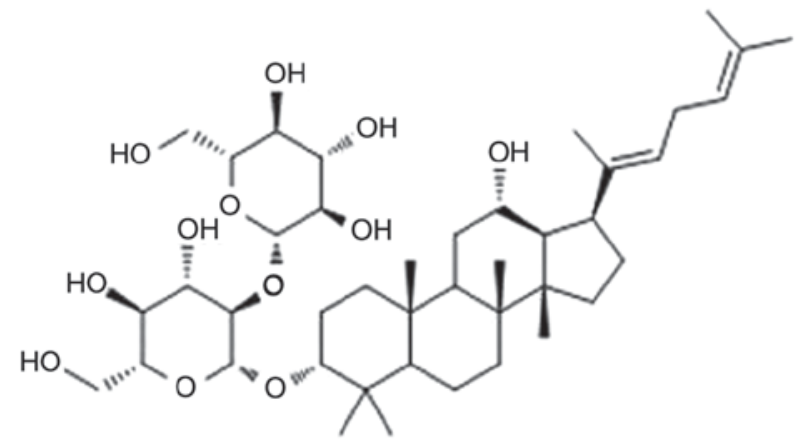

Figure 1. Chemical structure of ginsenoside Rg5.

Tris (pH 8.0), $150 \mathrm{mmol} / 1 \mathrm{NaCl}, 5 \%$ glycerol, $5 \mathrm{mmol} / \mathrm{l}$ EDTA, $1 \%$ Triton X-100, $25 \mathrm{mmol} / \mathrm{l} \mathrm{NaF}, 2 \mathrm{mmol} / 1 \mathrm{Na}_{2} \mathrm{VO}_{4}, 10 \mu \mathrm{g} / \mathrm{ml}$ aprotinin, $10 \mu \mathrm{g} / \mathrm{ml}$ pepstatin and $10 \mu \mathrm{g} / \mathrm{ml}$ leupeptin. The equal amounts of cell lysates were frozen, thawed three times and then centrifuged at $15,000 \mathrm{xg}$ for $10 \mathrm{~min}$ at $4^{\circ} \mathrm{C}$ in order to remove the insoluble pellet material. Protein determination was performed using the BCA protein assay kit. SDS-PAGE was performed on 12 or $15 \%$ gels according to the protein molecular weight and a 5\% stacking gel. The proteins on the gels were then transferred to prepared polyvinylidene difluoride membranes. Subsequently, the membranes were blocked for $\sim 2 \mathrm{~h}$ at $37^{\circ} \mathrm{C}$ in Tris-buffered saline containing $0.5 \%$ Tween-20 (TBST) and 5\% fat-free dried milk, and then incubated with the corresponding antibodies overnight at $4^{\circ} \mathrm{C}$. The membranes were washed three times with TBST and incubated with secondary antibodies at room temperature for $1 \mathrm{~h}$. The Hypersensitive Fluorescence and Chemiluminescence Imaging System (Clinx Science Instruments Co., Ltd., Shanghai, China) was used to visualize the signals. Band density was measured using Cell Quest Research software (version 3.3; BD Biosciences, Franklin Lakes, NJ, USA) and normalized to $\beta$-actin.

Inhibitor and activator of PI3K treatments. Eca-109 cells were co-treated with $\operatorname{Rg} 5(10 \mu \mathrm{M})$ and the PI3K-specific inhibitor LY294002 $(20 \mu \mathrm{M})$ or the PI3K-specific activator IGF-1 (100 ng/ml) for $24 \mathrm{~h}$. Cell apoptosis was then analyzed using a flow cytometer and the Annexin V-FITC/PI apoptosis assay kit. Protein levels were assessed via western blotting, as described earlier.

Statistical analysis. Data were analyzed by one-way analysis of variance, followed by Student-Newman-Keuls test, and each value was expressed as the mean \pm standard deviation. Statistical analysis was performed on IBM SPSS software (version 22.0). $\mathrm{P}<0.05$ was considered to indicate a statistically significant difference.

\section{Results}

Ginsenoside Rg5 inhibits the proliferation of Eca-109 cells. The anti-proliferative effect of ginsenoside Rg5 on Eca-109 cells was measured by treating the cells with different concentrations of ginsenoside $\operatorname{Rg} 5(2,4,8,16$ and $32 \mu \mathrm{M})$ for $24 \mathrm{~h}$. The results revealed that ginsenoside $\operatorname{Rg} 5$ significantly inhibited

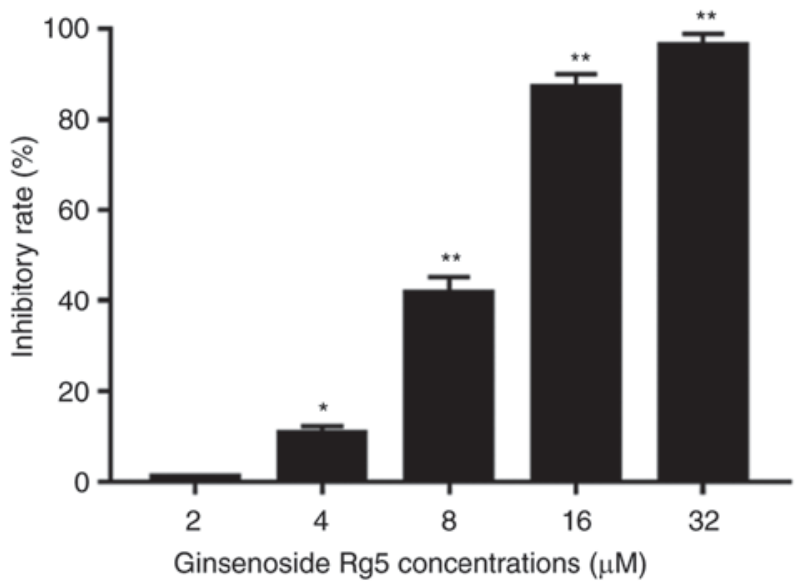

Figure 2. Effects of ginsenoside $\operatorname{Rg} 5$ on the viability of Eca-109 cells Eca-109 cells were plated at 2,000 cells/well in 96-well plates, and a Cell Counting Kit- 8 assay was performed to determine the cell inhibition rates following treatment with ginsenoside Rg5 for $24 \mathrm{~h}$. Concentration-dependent inhibition of Eca-109 cell growth was observed. Data are presented as the mean \pm standard deviation. ${ }^{*} \mathrm{P}<0.05$ and ${ }^{* *} \mathrm{P}<0.01$, vs. the untreated group.

the proliferation of Eca-109 cells in a concentration-dependent manner. The $\mathrm{IC}_{50}$ value of ginsenoside $\mathrm{Rg} 5$ for inhibiting Eca-109 cell proliferation was $8.245 \mu \mathrm{mol} / 1$ (Fig. 2).

Ginsenoside Rg5 induces apoptosis in Eca-109 cells. In order to determine whether the anti-proliferative effects of Rg5 were associated with the induction of apoptosis, Eca-109 cells were treated with $0-20 \mu \mathrm{M}$ ginsenoside Rg5 for $24 \mathrm{~h}$, and the Annexin V-FITC/PI apoptosis assay kit was used to determine the rates of Rg5-induced apoptosis. As shown in Fig. 3A, treatment with ginsenoside $\operatorname{Rg} 5$ at 5, 10 and $20 \mu \mathrm{M}$ induced a significant increase in apoptosis compared with the control group.

Ginsenoside Rg5 induces the cleavage of caspase-3, -8 and -9, and the phosphorylation of Akt in Eca-109 cells. The activation of specific caspases, including caspase- 8 and -9 , and the downstream effector caspase-3 were analyzed by western blotting. The results revealed that the levels of cleaved caspase-3, -8 and -9 increased following treatment with ginsenoside Rg5 in a dose-dependent manner (Fig. 3B). In addition, the proteolytic cleavage of PARP was increased. The levels of the pro-apoptotic protein Bax and the anti-apoptotic protein $\mathrm{Bcl}-2$ were also measured. The results indicated that the ratio of Bcl-2/Bax expression decreased following ginsenoside Rg5 treatment. The PI3K/Akt signaling pathway is considered to be an important upstream apoptotic pathway; thus, this was also examined in the present study. Western blot analysis revealed that Eca-109 cells treated with ginsenoside $\operatorname{Rg} 5$ (5, 10 and $20 \mu \mathrm{M})$ presented significantly inhibited expression of p-Akt (Fig. 3B). It was speculated that the promotion of apoptosis by $\operatorname{Rg} 5$ may be associated with the downregulation of the PI3K/Akt pathway.

Ginsenoside Rg5 decreases the mitochondrial transmembrane potential of Eca-109 cells. The decrease in mitochondrial transmembrane potential serves an important role in the progression of apoptosis. Rhodamine 123 is a lipophilic cationic fluorescent 
A

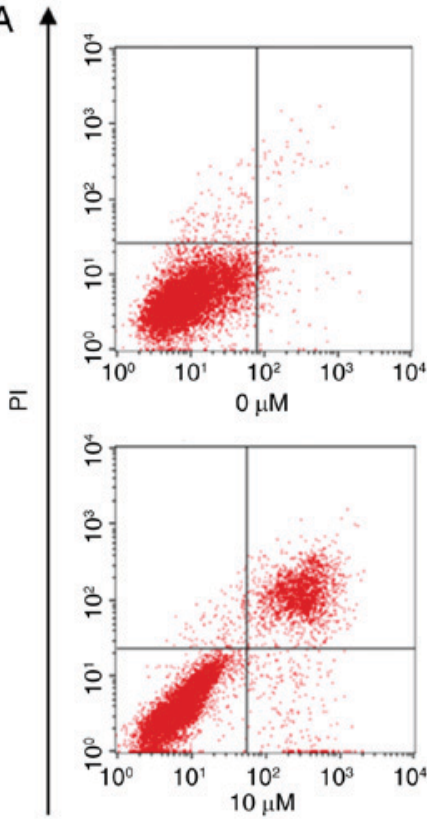

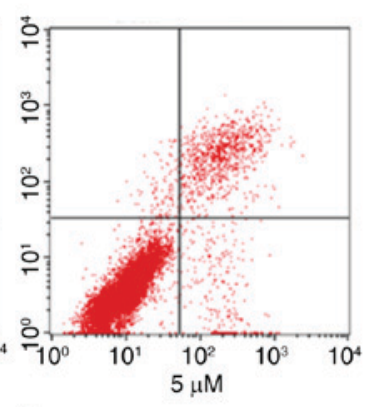

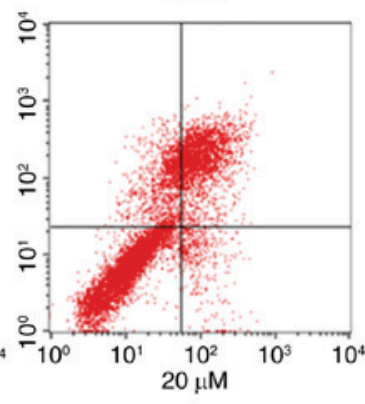

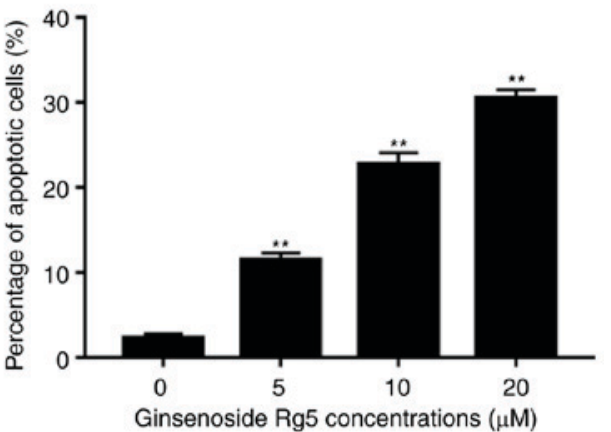

Annexin V-FITC

B
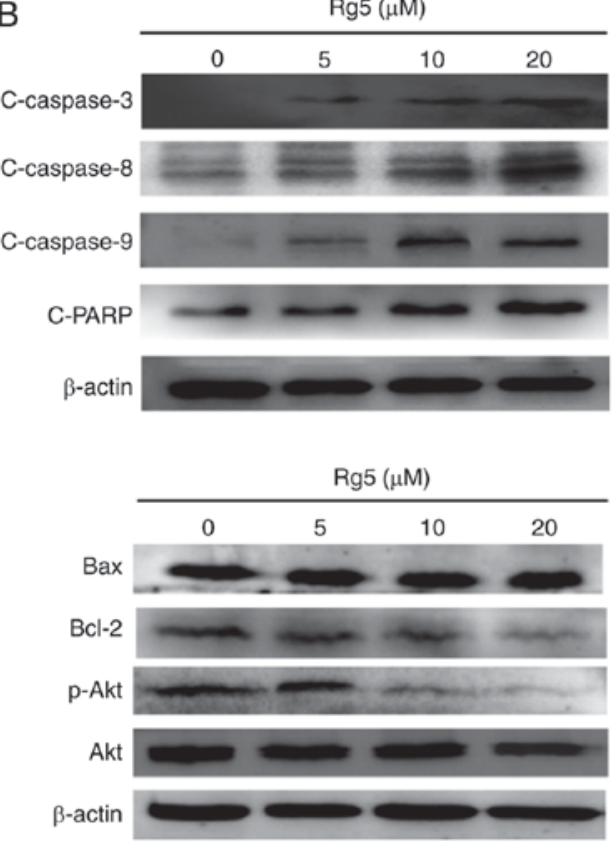
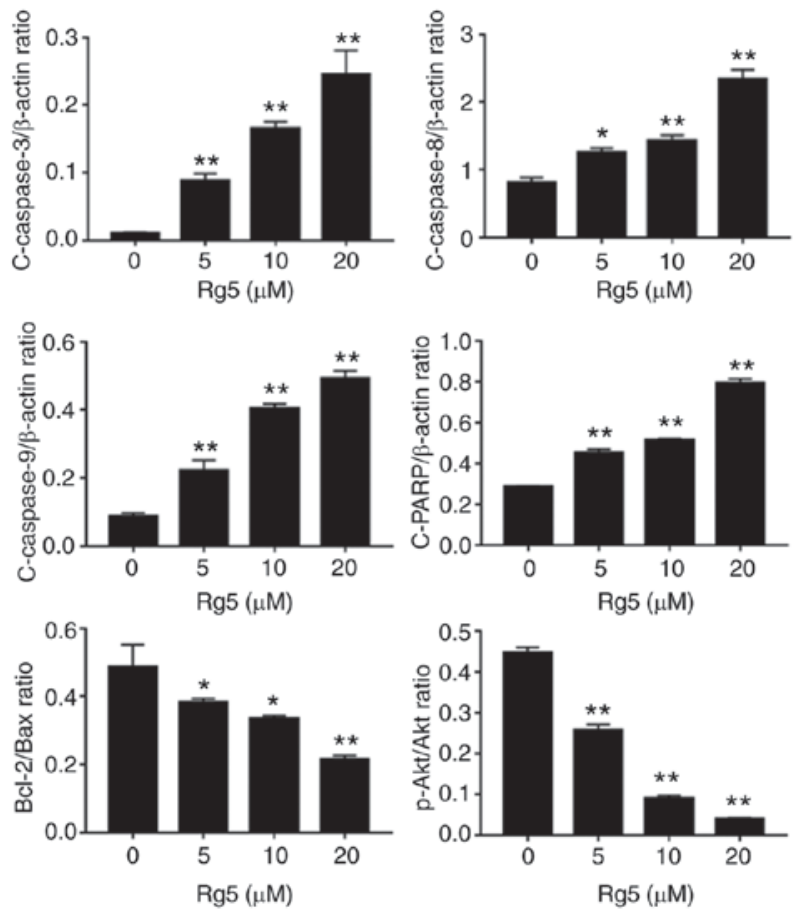
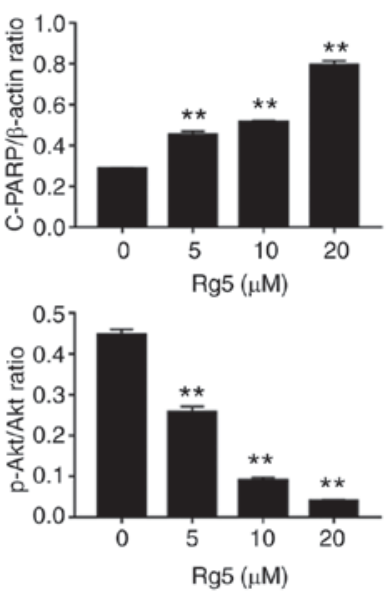

Figure 3. Ginsenoside Rg5 induces apoptosis in Eca-109 cells. (A) Annexin V-FITC/PI apoptosis assay kit was used to determine the rate of Rg5-induced apoptosis following treatment with ginsenoside Rg5 for $24 \mathrm{~h}$. A concentration-dependent increase in Eca-109 cell apoptosis was observed. (B) Cleaved caspase-3, -8 and -9, Bcl-2, Bax, Akt and p-Akt protein expression levels were analyzed by western blot analysis. The quantified results are presented in terms of the ratio of cleaved caspase- $3 / 8 / 9$ to $\beta$-actin, $\mathrm{Bcl}-2$ to Bax, and p-Akt to Akt. Data are presented as the mean \pm standard deviation. ${ }^{*} \mathrm{P}<0.05$ and ${ }^{* *} \mathrm{P}<0.01$, vs. the untreated group. FITC, fluorescein isothiocyanate; PI, propidium iodide; Bcl-2, B-cell lymphoma 2; Bax, Bcl-2-associated X protein; p-, phosphorylated; Akt, protein kinase B.

probe that can pass through a living cell membrane. Rhodamine 123 has a positive charge due to electrical adsorption and can be used to specifically label the mitochondria (19). In the present study, the results revealed that treatment with ginsenoside $\mathrm{Rg} 5$ at 5, 10 and $20 \mu \mathrm{M}$ significantly reduced the mitochondrial transmembrane potential in Eca-109 cells $(81.69 \pm 1.414$, $70.12 \pm 1.957$ and $48.63 \pm 1.224 \%$, respectively) when compared with the control group (89.85 $\pm 1.829 \%$; $\mathrm{P}<0.05$; Fig. 4).
Ginsenoside Rg5 increases cytoplasmic calcium levels in Eca-109 cells. As a major intracellular messenger, calcium is involved in regulating the physiological activities of numerous types of cells and tissues. The fluorescent probe Fluo-3/AM enters the cell and generates fluorescence at the excitation wavelength of $488 \mathrm{~nm}$, and its intensity is proportional to the concentration of intracellular free calcium ions (20). The results of the current study revealed that, following 24-h 

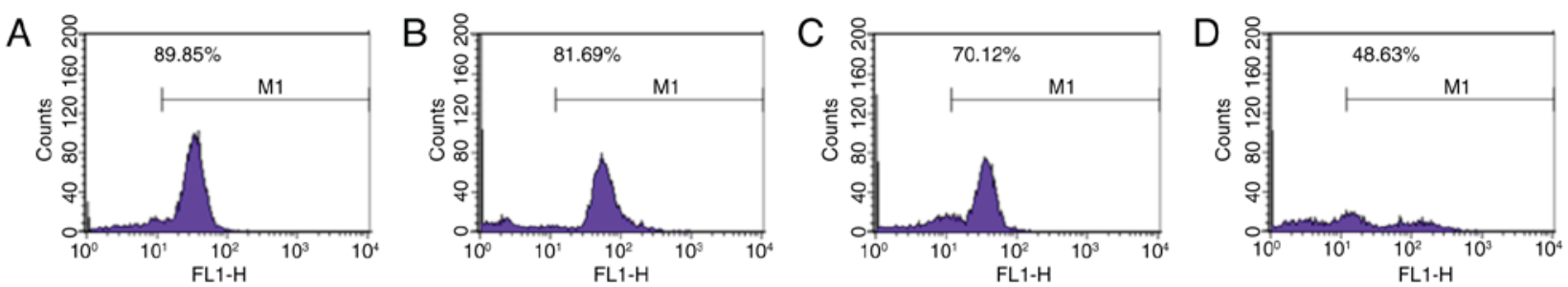

Figure 4. Effects of ginsenoside Rg5 on the mitochondrial membrane potential of Eca-109 cells. Eca-109 cells were treated with different concentrations of Rg5 for $24 \mathrm{~h}$, and flow cytometry was performed to analyze the mitochondrial membrane potential using fluorescent rhodamine 123 . Results are presented for cells treated with (A) medium only, or (B) $5 \mu \mathrm{M}$, (C) $10 \mu \mathrm{M}$ and (D) $20 \mu \mathrm{M}$ ginsenoside Rg5.

treatment with Rg5, the cytoplasmic calcium levels of Eca-109 cells were significantly increased in a dose-dependent manner, compared with the control group levels, as observed by the enhanced fluorescence intensity (Fig. 5).

Inhibition of the PI3K/Akt signaling pathway induces the anti-apoptotic effects of Rg5, while activation of the pathway inhibits this effect. The present study then examined whether the PI3K/Akt signaling pathway is important in the anti-apoptotic effect of Rg5. Eca-109 cells were treated with the PI3K inhibitor LY294002 or with the PI3K activator IGF-1. Co-treatment with ginsenoside Rg5 and LY294002 induced apoptosis when compared with the group treated with $\operatorname{Rg} 5$ alone (Fig. 6A), while it also markedly increased the levels of cleaved caspase-9 and cleaved PARP (Fig. 6B). In addition, LY294002 significantly lowered the expression levels of p-Akt and Bcl-2. Furthermore, co-treatment with IGF-1 markedly inhibited the anti-apoptotic effect of Rg5 (Fig. 6A). The cleavage of caspase- 9 and PARP caused by $\mathrm{Rg} 5$ was weakened by IGF-1; however, the decline in $\mathrm{p}-\mathrm{Akt}$ and $\mathrm{Bcl}-2$ protein expression was reversed (Fig. 6B). These results indicated that ginsenoside Rg5 induced Eca-109 cell apoptosis via the PI3K/Akt signaling pathway.

\section{Discussion}

Recently, a number of traditional Chinese medicine agents have been utilized for combination and adjuvant tumor treatment in order to reduce the side effects of therapy. With the development of molecular biology and in-depth research, the anti-tumor mechanism of ginseng is now better understood. In total, 46 potential target genes of (20S) G-Rh2 have been identified by performing phage display screening with the T7 select human liver tumor cDNA phage library (21). This indicates that ginsenosides may be multi-targeting drugs, triggering various anti-tumor pathways.

Several previous studies have confirmed that ginsenosides exert an anti-tumor effect through apoptotic signaling pathways. For instance, it has been reported that ginsenoside $\mathrm{Rg} 3$ induces apoptosis in human glioblastoma cells through the mitogen-activated protein kinase kinase signaling pathway (22). In addition, apoptosis is induced in cervical cancer cells via the mitochondrial pathway by the compound JRS-15 (23). The anti-tumor effect of Rg5 in cervical cancer (24), breast cancer (25) and hepatoma (9) cells has also been explored previously; however, to the best of our knowledge, no previous studies have investigated esophageal cancer

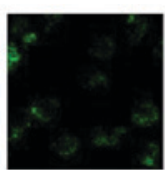

$0 \mu \mathrm{M}$

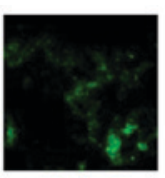

$5 \mu \mathrm{M}$

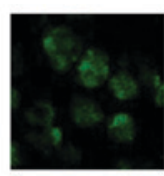

$10 \mu \mathrm{M}$

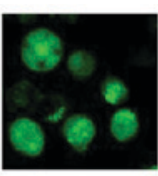

$20 \mu \mathrm{M}$

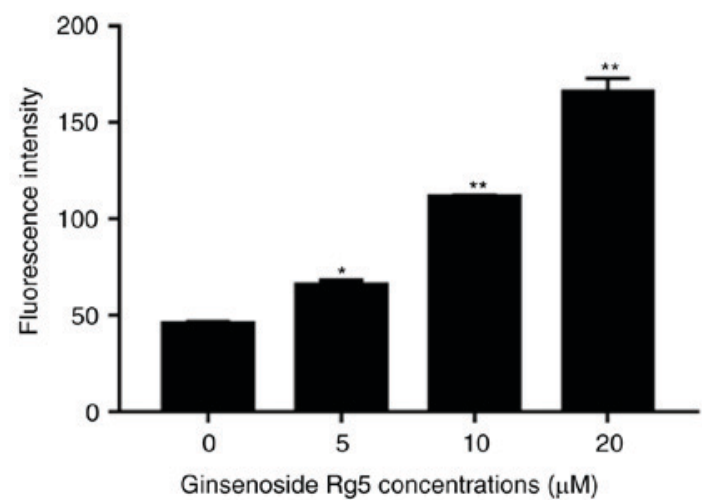

Figure 5. Ginsenoside Rg5 increases the cytoplasmic calcium levels of Eca-109 cells. Eca-109 cells were treated with different concentrations of $\mathrm{Rg} 5$ for $24 \mathrm{~h}$ and then incubated with Fluo-3/AM. Representative images (x400 oil immersion objective) of confocal microscopy are presented, as well as a histogram of the data analyzed by the affiliated software. Data are presented as the mean \pm standard deviation. ${ }^{*} \mathrm{P}<0.05$ and ${ }^{* *} \mathrm{P}<0.01$, vs. untreated group. AM, acetoxymethyl.

cells. In addition to research into its anti-tumor effects, the protective effect of ginsenoside $\operatorname{Rg} 5$ has received increasing attention in recent years. Previous studies have demonstrated that ginsenoside $\operatorname{Rg} 5$ significantly improved cisplatin-associated chemotherapy-induced nephrotoxicity (26). Its roles in improving immunity and protecting the heart have also been confirmed $(27,28)$. Combined with the current research in progress, it is clear that ginsenoside $\operatorname{Rg} 5$ serves a wide range of protective anti-tumor effects and has great potential for clinical application as an anti-tumor drug. The aim of the present study was to elucidate the apoptotic effect of $\operatorname{Rg} 5$ on esophageal cancer cells and its possible mechanism. In the present study, it was identified that $\operatorname{Rg} 5$ inhibited the proliferation of esophageal cancer cells and promoted apoptosis. Significant increases in the activity of caspase-3, -8, -9 and PARP were observed.

It has been reported that the decrease in the mitochondrial transmembrane potential is associated with intrinsic apoptotic pathways that increase the permeability due to the release of cytochrome $\mathrm{c}$ in the cytoplasm (29). The mitochondrial permeability transition pore (MPTP) is located in the 

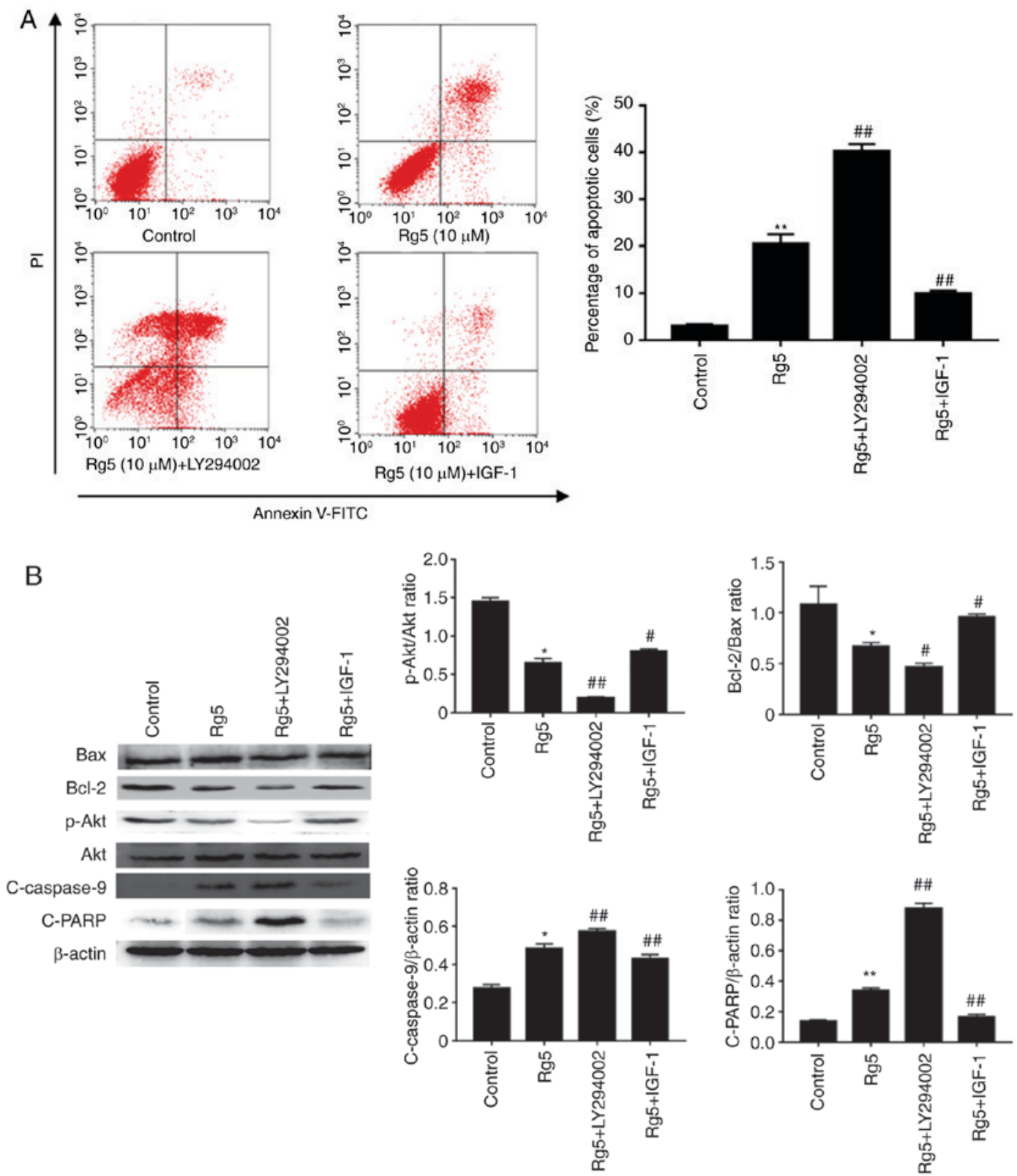

Figure 6. LY294002 enhances the anti-apoptotic effects of Rg5 and IGF-1 inhibits these effects. (A) Annexin V-FITC/PI apoptosis assay kit was used to determine the apoptotic rate of the untreated, $\mathrm{Rg} 5$-treated $(10 \mu \mathrm{M})$, LY294002-treated $(20 \mu \mathrm{M})$ and IGF-1-treated $(100 \mathrm{ng} / \mathrm{ml})$ groups following treatment for $24 \mathrm{~h}$. (B) Cleaved caspase-9, cleaved PARP, Bcl-2, Bax, Akt and p-Akt protein expression levels were analyzed by western blot analysis. The quantified results are presented in terms of the ratio of cleaved caspase-9 to $\beta$-actin, Bcl-2 to Bax, and p-Akt to Akt. Data are presented as the mean \pm standard deviation. ${ }^{*} \mathrm{P}<0.05$ and ${ }^{* *} \mathrm{P}<0.01$, vs. untreated group; ${ }^{*} \mathrm{P}<0.05$ and ${ }^{\# \#} \mathrm{P}<0.01$, vs. the Rg5-treated group. IGF-1, insulin-like growth factor 1 ; FITC, fluorescein isothiocyanate; PI, propidium iodide; PARP, poly(adenosine diphosphate-ribose) polymerase; Bcl-2, B-cell lymphoma 2; Bax, Bcl-2-associated X protein; p-, phosphorylated; Akt, protein kinase B.

mitochondrial inner and outer membrane, and is composed of a variety of protein non-selective complexes (30). Its periodic opening serves an important role in maintaining homeostasis and electrochemical balance in the mitochondria. When the mitochondrial transmembrane potential decreases, apoptosis is eventually induced in cells following opening of the MPTP. This indicates that the decrease in transmembrane potential may be associated with the opening of the MPTP (31). Prolonged opening of the MPTP leads to the reduction of the $\mathrm{H}^{+}$concentration gradient inside and outside of the mitochondrial membrane, while the transmembrane potential gradually decreases (32). The respiratory chain is uncoupled and the synthesis of adenosine triphosphate (ATP) is interrupted, further promoting the release of cytochrome c, apoptosis-inducing factor and protein kinases, such as Akt, into the cytoplasm (33). In the present study, ginsenoside $\operatorname{Rg} 5$ treatment induced a significant decrease in the mitochondrial transmembrane potential of Eca-109 cells, thereby promoting apoptosis via intrinsic pathways, as measured by flow cytometry.

$\mathrm{Ca}^{2+}$ serves a major role in triggering mitosis in various types of cells, as well as in regulating cell death (34). Low cytoplasmic $\mathrm{Ca}^{2+}$ concentration is critical for maintaining normal cellular function, whereas an overload of cellular $\mathrm{Ca}^{2+}$ is highly toxic, leading to extensive activation of proteases and phospholipases (35). Mitochondria and ATPase pumps 
serve an important role in the preservation of $\mathrm{Ca}^{2+}$ levels and are closely associated with the release of $\mathrm{Ca}^{2+}$. The release of intracellular $\mathrm{Ca}^{2+}$ or increased $\mathrm{Ca}^{2+}$ influx from the mitochondria or endoplasmic reticulum may serve as an apoptotic signal, thereby leading to apoptosis, particularly via extrinsic pathways. While the release of $\mathrm{Ca}^{2+}$ may lead to the breakdown of organelles, activation of apoptosis-associated transcription factors triggers apoptosis (36). The present study detected changes in $\mathrm{Ca}^{2+}$ levels using Fluo-3/AM, which can enter into the cell and generate fluorescence at the excitation wavelength of $488 \mathrm{~nm}$, following binding with intracellular free calcium ions. The results of the present study revealed that $\mathrm{Rg} 5$ increased the intracellular $\mathrm{Ca}^{2+}$ levels and caused cell apoptosis.

The PI3K/Akt signaling pathway is associated with numerous cellular functions, including cell viability, proliferation and apoptosis, while it is also involved in cell survival pathways $(37,38)$. Inhibition of this pathway can decrease the phosphorylation of Akt (39). The PI3K/Akt signaling pathway is normally activated in human cancer. Previous studies have reported that the inhibition of PI3K/Akt signaling pathway activity can effectively inhibit the proliferation and invasion of breast cancer cells (40). Furthermore, inhibition of PI3K/Akt signaling in lung cancer induces apoptosis and arrests the cell cycle (41). The present study further revealed that $\operatorname{Rg} 5$ treatment resulted in a concentration-dependent decrease in the level of p-Akt in Eca109 cells. This may indicate that the pro-apoptotic effect of $\operatorname{Rg} 5$ is associated with the inhibition of the PI3K/Akt pathway. To further determine whether the $\mathrm{PI} 3 \mathrm{~K} / \mathrm{Akt}$ signaling pathway is important in the apoptosis of esophageal cancer cells, Eca-109 cells were co-treated with Rg5 and the PI3K inhibitor LY294002, and the expression levels of apoptosis markers were detected. Compared with Rg5 alone, co-treatment with LY294002 significantly inhibited the level of p-Akt, and in addition, significantly decreased the expression of $\mathrm{Bcl} 2$; however, it also induced the expression of cleaved caspase-9. The PI3K promoter IGF-1 was also used to treat cells to determine whether it was able to reverse $\mathrm{Rg} 5$-induced apoptosis. The results revealed that IGF-1 treatment reversed the decrease in p-Akt induced by $\mathrm{Rg} 5$, while it significantly reversed the decrease in Bcl-2 expression and increase in cleaved caspase- 9 expression when compared with Rg5 treatment alone.

In conclusion, the present study revealed that ginsenoside Rg5 inhibited the proliferation and induced the apoptosis of human esophageal cancer cells. In addition, its role in promoting tumor apoptosis was associated with the downregulation of the PI3K/Akt signaling pathway. However, the present study had certain limitations. The specific signaling pathways involved in ginsenoside Rg5-induced apoptosis in esophageal cancer cells require further verification. Furthermore, in vivo experiments are required to understand the anti-tumor effects of $\operatorname{Rg} 5$ and to conduct pharmacokinetic studies.

\section{Acknowledgements}

The authors would like to thank Professor Yinghua Jin (College of Life Science, Jilin University, Changchun, China) for providing ginsenoside Rg5.

\section{Funding}

The present study was supported by the Scientific and Technical Foundation of Jilin Province (grant no. 20160204022YY).

\section{Availability of data and materials}

The datasets used and/or analyzed during the current study are available from the corresponding author on reasonable request.

\section{Authors' contributions}

LL and HR, DZ conceived and designed the study. DZ, AW and JF performed the experiments. QZ and DZ analyzed the data. DZ and LL wrote the manuscript. All authors read and approved the manuscript.

\section{Ethics approval and consent to participate}

Not applicable.

\section{Patient consent for publication}

Not applicable.

\section{Competing interests}

The authors declare that they have no competing interests.

\section{References}

1. Yun TK, Lee YS, Lee YH, Kim SI and Yun HY: Anticarcinogenic effect of Panax ginseng C.A. Meyer and identification of active compounds. J Korean Med Sci 16 (Suppl): S6-S18, 2001.

2. De Souza LR, Jenkins AL, Sievenpiper JL, Jovanovski E, Rahelić D and Vuksan V: Korean red ginseng (Panax ginseng C.A. Meyer) root fractions: Differential effects on postprandial glycemia in healthy individuals. J Ethnopharmacol 137: 245-250, 2011.

3. Varjas T, Nowrasteh G, Budán F, Nadasi E, Horváth G, Makai S, Gracza T, Cseh J and Ember I: Chemopreventive effect of Panax ginseng. Phytother Res 23: 1399-1403, 2009.

4. Helms S: Cancer prevention and therapeutics: Panax ginseng. Altern Med Rev 9: 259-274, 2004.

5. Shin HR, Kim JY, Yun TK, Morgan G and Vainio H: The cancer-preventive potential of Panax ginseng: A review of human and experimental evidence. Cancer Causes Control 11: $565-576,2000$.

6. Kim SN, Ha YW, Shin H, Son SH, Wu SJ and Kim YS: Simultaneous quantification of 14 ginsenosides in Panax ginseng C.A. Meyer (Korean red ginseng) by HPLC-ELSD and its application to quality control. J Pharm Biomed Anal 45: 164-170, 2007.

7. Nag SA, Qin JJ, Wang W, Wang MH, Wang $\mathrm{H}$ and Zhang R: Ginsenosides as anticancer agents: In vitro and in vivo activities, structure-activity relationships, and molecular mechanisms of action. Front Pharmacol 3: 25, 2012.

8. Lee KY, Lee YH, Kim SI, Park JH and Lee SK: Ginsenoside-Rg5 suppresses cyclin E-dependent protein kinase activity via up-regulating p21Cip/WAF1 and down-regulating cyclin E in SK-HEP-1 cells. Anticancer Res 17: 1067-1072, 1997.

9. Shin YW, Bae EA and Kim DH: Inhibitory effect of ginsenoside $\mathrm{Rg} 5$ and its metabolite ginsenoside Rh3 in an oxazolone-induced mouse chronic dermatitis model. Arch Pharm Res 29: 685-690, 2006.

10. Kim EJ, Jung IH, Van Le TK, Jeong JJ, Kim NJ and Kim DH: Ginsenosides Rg5 and Rh3 protect scopolamine-induced memory deficits in mice. J Ethnopharmacol 146: 294-299, 2013.

11. Lee YY,Park JS,Jung JS,Kim DHandKimHS: Anti-inflammatory effect of ginsenoside Rg5 in lipopolysaccharide-stimulated BV2 microglial cells. Int J Mol Sci 14: 9820-9833, 2013. 
12. Ferlay J, Soerjomataram I, Dikshit R, Eser S, Mathers C, Rebelo M, Parkin DM, Forman D and Bray F: Cancer incidence and mortality worldwide: Sources, methods and major patterns in GLOBOCAN 2012. Int J Cancer 136: E359-E386, 2015.

13. Song Y, Li L, Ou Y, Gao Z, Li E, Li X, Zhang W, Wang J, Xu L, Zhou Y, et al: Identification of genomic alterations in oesophageal squamous cell cancer. Nature 509: 91-95, 2014.

14. Tachibana M, Kinugasa S, Hirahara $\mathrm{N}$ and Yoshimura $\mathrm{H}$ : Lymph node classification of esophageal squamous cell carcinoma and adenocarcinoma. Eur J Cardiothorac Surg 34 427-431, 2008

15. Ouyang L, Shi Z, Zhao S, Wang FT, Zhou TT, Liu B and Bao JK: Programmed cell death pathways in cancer: A review of apoptosis, autophagy and programmed necrosis. Cell Prolif 45: 487-498, 2012

16. Streeter OE Jr, Martz KL, Gaspar LE, Delrowe JD, Asbell SO, Salter MM and Roach M III: Does race influence survival for esophageal cancer patients treated on the radiation and chemotherapy arm of RTOG \#85-01? Int J Radiat Oncol Biol Phys 44: 1047-1052, 1999.

17. Danial NN and Korsmeyer SJ: Cell death: Critical control points. Cell 116: 205-219, 2004.

18. Schönfelder U, Radestock A, Elsner P and Hipler UC: Cyclodextrin-induced apoptosis in human keratinocytes is caspase- 8 dependent and accompanied by mitochondrial cytochrome c release. Exp Dermatol 15: 883-890, 2006.

19. Kale J, Liu Q, Leber B and Andrews DW: Shedding light on apoptosis at subcellular membranes. Cell 151: 1179-1184, 2012

20. Robinson JA, Jenkins NS, Holman NA, Roberts-Thomson SJ and Monteith GR: Ratiometric and nonratiometric Ca2+ indicators for the assessment of intracellular free $\mathrm{Ca} 2+$ in a breast cancer cell line using a fluorescence microplate reader. J Biochem Biophys Methods 58: 227-237, 2004.

21. Wang YS, Lin Y, Li H, Li Y, Song Z and Jin YH: The identification of molecular target of (20S) ginsenoside Rh2 for its anti-cancer activity. Sci Rep 7: 12408, 2017.

22. Choi YJ, Lee HJ, Kang DW, Han IH, Choi BK and Cho WH: Ginsenoside Rg3 induces apoptosis in the U87MG human glioblastoma cell line through the MEK signaling pathway and reactive oxygen species. Oncol Rep 30: 1362-1370, 2013.

23. Sun C, Guo XX, Zhu D, Xiao C, Bai X, Li Y, Zhan Z, Li XL, Song ZG and Jin YH: Apoptosis is induced in cancer cells via the mitochondrial pathway by the novel xylocydine-derived compound JRS-15. Int J Mol Sci 14: 850-870, 2013.

24. Liang LD, He T, Du TW, Fan YG, Chen DS and Wang Y: Ginsenoside-Rg5 induces apoptosis and DNA damage in human cervical cancer cells. Mol Med Rep 11: 940-946, 2015.

25. Kim SJ and Kim AK: Anti-breast cancer activity of Fine Black ginseng (Panax ginseng Meyer) and ginsenoside Rg5. J Ginseng Res 39: 125-134, 2015.

26. Li W, Yan MH, Liu Y, Liu Z, Wang Z, Chen C, Zhang J and Sun YS: Ginsenoside Rg5 Ameliorates Cisplatin-induced nephrotoxicity in mice through inhibition of inflammation, oxidative Stress, and apoptosis. Nutrients 8: pii: E566, 2016.

27. Yang YL, Li J, Liu K, Zhang L, Liu Q, Liu B and Qi LW: Ginsenoside rg5 increases cardiomyocyte resistance to ischemic injury through regulation of mitochondrial hexokinase-II and dynamin-related protein 1. Cell Death Dis 8: e2625, 2017.
28. Shin MS, Song JH, Choi P, Lee JH, Kim SY, Shin KS, Ham J and Kang KS: Stimulation of innate immune function by Panax ginseng after heat processing. J Agric Food Chem 66: 4652-4659, 2018

29. Heiskanen KM, Bhat MB, Wang HW, Ma J and Nieminen A: Mitochondrial depolarization accompanies cytochrome c release during apoptosis in PC6 cells. J Biol Chem 26: 5654-5658, 1999.

30. Chen H, Xu J, Lv Y, He P, Liu C, Jiao J, Li S, Mao X and Xue X Proanthocyanidins exert a neuroprotective effect via ROS/JNK signaling in MPTP-induced Parkinson's disease models in vitro and in vivo. Mol Med Rep 18: 4913-4921, 2018.

31. Rasheed MZ, Tabassum H and Parvez S: Mitochondrial permeability transition pore: A promising target for the treatment of Parkinson's disease. Protoplasma 254: 33-42, 2017

32. Wu HY, Huang CH, Lin YH, Wang CC and Jian TR: Cannabidiol induced apoptosis in human monocytes through mitochondrial permeability transition pore-mediated ROS production. Free Radic Biol Med 124: 311-318, 2018.

33. Shibayama-Imazu T, Aiuchi $\mathrm{T}$ and Nakaya K: Vitamin K2-mediated apoptosis in cancer cells: Role of mitochondrial transmembrane potential. Vitam Horm 78: 211-226, 2008.

34. Giorgi $\mathrm{C}$, Romagnoli A, Pinton $\mathrm{P}$ and Rizzuto R: Ca2+ signaling, mitochondria and cell death. Curr Mol Med 8: 119-130, 2008.

35. Pinton P, Giorgi C, Siviero R, Zecchini E and Rizzuto R: Calcium and apoptosis: ER-mitochondria $\mathrm{Ca} 2+$ transfer in the control of apoptosis. Oncogene 27: 6407-6418, 2008.

36. Oppenheim R: Naturally occurring cell death during neural development. Trends Neurosci 8: 487-493, 1985.

37. Granado-Serrano AB, Martin MA, Bravo L, Goya L and Ramos S: Quercetin induces apoptosis via caspase activation, regulation of $\mathrm{Bcl}-2$, and inhibition of PI-3-kinase/Akt and ERK pathways in a human hepatoma cell line (HepG2). Nutr 136: 2715-2721, 2006

38. Xiang T, Fang Y and Wang SX: Quercetin suppresses HeLa cells by blocking PI3K/Akt pathway. J Huazhong Univ Sci Technol Med Sci 34: 740-744, 2014.

39. Wong MH, Xue A, Baxter RC, Pavlakis N and Smith RC: Upstream and downstream co-inhibition of mitogen-activated protein kinase and PI3K/Akt/mTOR pathways in pancreatic ductal adenocarcinoma. Neoplasia 18: 425-435, 2016.

40. Dillon LM, Bean JR, Yang W, Shee K, Symonds LK, Balko JM, McDonald WH, Liu S, Gonzalez-Angulo AM, Mills GB, et al: P-REX1 creates a positive feedback loop to activate growth factor receptor, PI3K/AKT and MEK/ERK signaling in breast cancer. Oncogene 34: 3968-3976, 2015.

41. RiquelmeE,Behrens C,LinHY,SimonG,Papadimitrakopoulou V, Izzo J, Moran C, Kalhor N, Lee JJ, Minna JD and Wistuba II: Modulation of EZH2 expression by MEK-ERK or PI3K-AKT Signaling in lung cancer is Dictated by different KRAS oncogene mutations. Cancer Res 76: 675-685, 2016.

This work is licensed under a Creative Commons Attribution-NonCommercial-NoDerivatives 4.0 International (CC BY-NC-ND 4.0) License. 